\title{
The Heidelberg iterative cloud retrieval utilities (HICRU) and its application to GOME data
}

\author{
M. Grzegorski ${ }^{1}$, M. Wenig ${ }^{2}$, U. Platt ${ }^{1}$, P. Stammes ${ }^{3}$, N. Fournier ${ }^{3}$, and T. Wagner ${ }^{1}$ \\ ${ }^{1}$ Institute of Environmental Physics, University of Heidelberg, Germany \\ ${ }^{2}$ NASA Goddard Space Flight Center, Greenbelt, Maryland, USA \\ ${ }^{3}$ KNMI, Climate Research and Seismology Department, de Bilt, The Netherlands
}

Received: 23 December 2006 - Published in Atmos. Chem. Phys. Discuss.: 7 March 2006

Revised: 24 July 2006 - Accepted: 30 August 2006 - Published: 5 October 2006

\begin{abstract}
Information about clouds, in particular the accurate identification of cloud free pixels, is crucial for the retrieval of tropospheric vertical column densities from space. The Heidelberg Iterative Cloud Retrieval Utilities (HICRU) retrieve effective cloud fraction using spectra of two instruments designed for trace gas retrievals from space: The Global Ozone Monitoring Experiment (GOME) on the European Remote Sensing Satellite (ERS-2) and the SCanning Imaging Absorption SpectroMeter for Atmospheric CHartographY (SCIAMACHY) on ENVISAT.

HICRU applies the widely used threshold method to the so-called Polarization Monitoring Devices (PMDs) with higher spatial resolution compared to the channels used for trace gas retrievals. Cloud retrieval and in particular the identification of cloud free pixels is improved by HICRU through a sophisticated, iterative retrieval of the thresholds which takes their dependency on different instrumental and geometrical parameters into account. The lower thresholds, which represent the surface albedo and strongly affect the results of the algorithm, are retrieved accurately through a four stage classification scheme using image sequence analysis.

The design and the results of the algorithm applied to GOME data are described and compared to several other cloud algorithms for GOME. The differences to other cloud algorithms are discussed with respect to the particular characteristics of the algorithms.
\end{abstract}

\section{Introduction}

The detection of cloud parameters like cloud coverage, cloud top pressure or cloud optical thickness from satellite is an important issue: 1.) for meteorology and the investigation of climate change and 2.) for the analysis of tropospheric trace gases from space relevant to environmental and climatologi-

Correspondence to: M. Grzegorski

(mgrzegor@iup.uni-heidelberg.de) cal issues. Although the retrieval of different cloud parameters is useful for trace gas retrievals, especially the accurate identification of completely cloud free regions is crucial due to the shielding effect, which causes an underestimation of the vertical column density of tropospheric trace gases measured by satellite.

There are already several algorithms retrieving cloud parameters using data of the Global Ozone Monitoring Experiment (GOME, see Sect. 2): The official GOME cloud product ICFA (Initial Cloud Fitting Algorithm, Kuze and Chance, 1994) and the FRESCO algorithm (Fast REtrieval Scheme for Clouds from the Oxygen-A-Band, Koelemeijer et al., 2001) use the GOME channels with moderate spectral resolution. There are also several algorithms using broad band spectrometer with higher spatial resolution, the so-called Polarization Monitoring devices (PMD) (see Table 4, Sect. 4).

Two different quantities are typically applied for cloud retrieval from GOME data: The first class of algorithms use the absorption of the $\mathrm{O}_{2}$-A-Band: since clouds reduce the penetration of light down to low layers of the atmosphere, the absorption of oxygen is reduced for a cloudy pixel compared to a cloud free measurement, where the absorption mainly depends on cloud coverage, cloud albedo and cloud top height. This approach is used by ICFA and FRESCO, but cannot be applied to the PMD instruments because of their insufficient spectral resolution. The major idea of the second class of algorithms is, that clouds can also be identified through the intensity of reflected light hardly affected by trace gas absorptions, because clouds are usually brighter than the surface. These intensities are mainly independent of cloud top height, but they also depend on cloud coverage and cloud albedo. This approach is applied using small spectral windows of the detectors with moderate spectral resolution (FRESCO) and by the algorithms using the PMD instruments (Table 4, Sect. 4). All these algorithms retrieve an effective cloud fraction, a parameter that combines cloud coverage (cloud abundance) of the pixel and cloud albedo.

Published by Copernicus GmbH on behalf of the European Geosciences Union. 


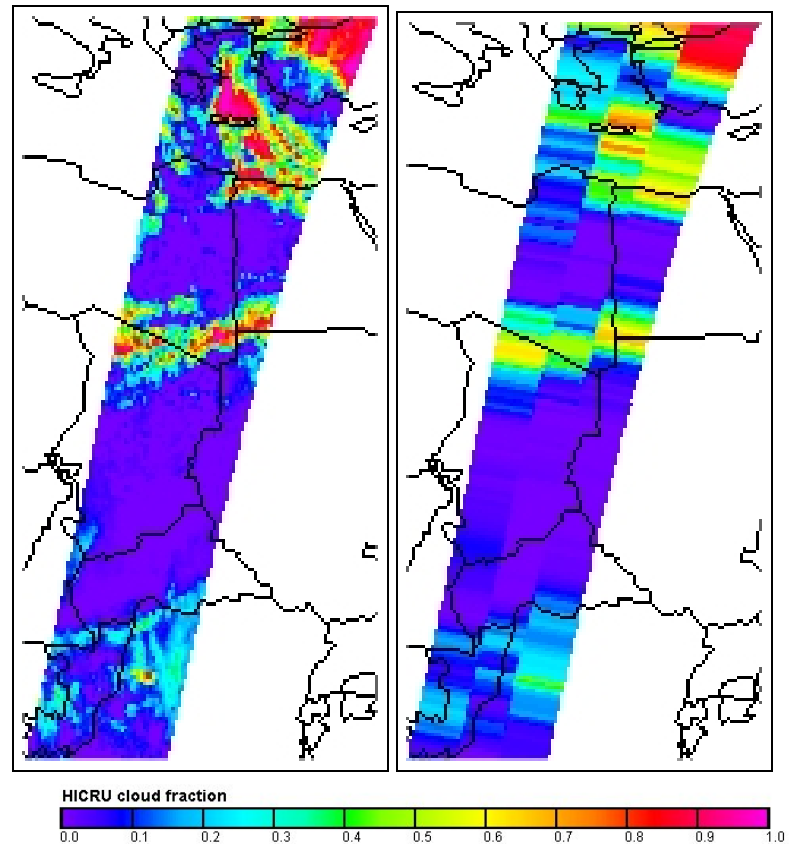

Fig. 1. HICRU cloud fraction on 6 January 2000, over central Africa, Sahara and the Mediterranean with original spatial resolution (left) and reduced spatial resolution (right). The right image has the same spatial resolution as the GOME channels with higher spectral resolution and each value is the average of 16 values of HICRU cloud fraction.

The first class of algorithms is used in two different ways: ICFA retrieves effective cloud fraction using the absorption of the $\mathrm{O}_{2}$-A-band directly, where the cloud top height is defined a priori using the ISCCP climatology (Schiffer and Rossow, 1983). This can create large errors in cloud fraction if the cloud top height deviates from the climatological average (Koelemeijer and Stammes, 1999). On the other hand, the $\mathrm{O}_{2}$-A-band approach is also used to retrieve cloud top height, where a combination of both approaches is used: an intensity-based effective cloud fraction is retrieved simultaneously (FRESCO) or beforehand (GOME Cloud retrieval AlgoriThm (GOMECAT, v. Bargen et al., 2000, Retrieval Of Cloud Information by a Neural Network, ROCINN, Loyola, 2004).

There are further cloud algorithms designed for other satellite platforms, which were also be applied to selected GOME data for validation purposes: The Semi-Analytical CloUd Retrieval Algorithm (SACURA) retrieves cloud top height and further cloud parameters for totally cloudy pixels using the $\mathrm{O}_{2}$-A-Band approach and intensities from different wavelength regions (Kokhanovsky et al., 2003; Rozanov and Kokhanovsky, 2004). Besides the methods described above, further quantities, e.g. the absorption bands of $\mathrm{O}_{4}$ and the Ring effect can be used for the retrieval of cloud parameters from GOME data (Wagner et al., 2003; de Beek et al., 2001; Acarreta et al., 2004; Joiner et al., 2004).

\section{The global ozone monitoring experiment}

The Global Ozone Monitoring Experiment (GOME) (Burrows et al., 1999) on board the ESA satellite ERS-2 provides data for the retrieval of vertical column densities of tropospheric trace gases (e.g. $\mathrm{NO}_{2}, \mathrm{SO}_{2}, \mathrm{HCHO}, \mathrm{H}_{2} \mathrm{O}$ ) using the DOAS technique (Platt, 1994; Burrows et al., 1999; Wagner et al., 2002). The satellite flies along a sun-synchronous polar orbit at an altitude of about $780 \mathrm{~km}$ and crosses the equator at 10:30 a.m. (local time). Global coverage is achieved every three days. The orbit of the satellite leads to an essentially constant relationship between the solar zenith angle and the latitude depending only on the seasonal shift in the position of the sun. GOME measures earthshine spectra in a nadir viewing geometry, i.e. it looks radially towards the earth. The earth's surface is scanned with an angular range of 31 degrees both in western and eastern direction corresponding to a cross track swath width of $960 \mathrm{~km}$. During each scan three subpixels are mapped extending $320 \mathrm{~km}$ east-west and $40 \mathrm{~km}$ north-south: subpixel 0 (east), subpixel 1 (center) and subpixel 2 (west). These three forescan pixels are followed by a backscan pixel (subpixel 3) with an extent of $960 * 40 \mathrm{~km}^{2}$. GOME consists of four spectrometers in UV/vis wavelength region with moderate spectral resolution $(0.2-0.4 \mathrm{~nm})$ used for the DOAS retrieval of trace gases. Furthermore, the GOME instrument bears three broad band detectors covering the UV (PMD1, 295-397 nm) and the visible wavelength region (PMD2, 397-580 nm and PMD3, 580-745 nm). These Polarization Monitoring Devices (PMDs) are mainly intended for measuring the polarization of the observed light. However, the PMDs can be read out more frequently than the channels with moderate spectral resolution. Thus, we receive 16 PMD measurements across each subpixel. This results in a higher spatial resolution of $20 \times 40 \mathrm{~km}^{2}$ (instead of $320 \times 40 \mathrm{~km}^{2}$ ), which makes the PMDs especially suitable for an intensity-based cloud retrieval from GOME data.

\section{The Heidelberg Iterative Cloud Retrieval Utilities (HICRU)}

The HICRU algorithm uses the PMDs of GOME to retrieve the effective cloud fraction, because of their higher spatial resolution compared to the channels with moderate spectral resolution. An important advantage of the higher spatial resolution is found in the strong influence of the surface albedo on the retrieved cloud fraction (Wenig, 2001). The determination of surface albedo requires an adequately large set of measurements referring to cloud free scenarios, but the probability of a cloud free measurement strongly depends on spatial resolution.

The most important application of HICRU is the accurate retrieval of tropospheric trace gases (e.g. Beirle et al., $2004 a, b, c)$. This requires a decrease of the spatial resolution 
to the pixel size of the channels with moderate spectral resolution, but we can retrieve at least an additional parameter describing cloud heterogeneity and obtain additional information about the spatial structure of cloud clusters. This is demonstrated by Fig. 1. Nevertheless, HICRU is also applied to studies directly focussed on cloud properties. An example is the analysis of the El-Niño phenomenon (Wagner et al., 2005). In this case we directly benefit from the higher spatial resolution of the PMD instruments.

\subsection{Application of the threshold method}

The HICRU algorithm is based on the widely used threshold method. First, lower thresholds $I_{\text {cloudfree }}$, representing the intensity of cloud free pixels, and upper thresholds $I_{\text {cloudy }}$, representing the intensity of completely cloudy pixels, are calculated. The cloud fraction CF is retrieved from the measured intensity $I_{\text {meas }}$ through linear interpolation between the thresholds:

$C F=\frac{I_{\text {meas }}-I_{\text {cloudfree }}}{I_{\text {cloudy }}-I_{\text {cloudfree }}}$

This interpolation assumes that a cloud is a lambertian reflector and that a GOME pixel can be divided into a cloud free part and a cloudy part, where the albedo of the cloudy part is implicitly determined by the upper thresholds. HICRU uses earthshine radiances divided by the cosine of the solar zenith angle and the solar spectrum from the operational data product.

The accuracy of PMD cloud algorithms critically depends on the quality of the calculated lower and upper thresholds. The accurate retrieval of the the lower thresholds is especially important for the detection of cloud free pixels, because the measured intensity is not only sensitive to the cloud coverage and the cloud albedo, but also to the surface albedo, which depends on surface type and the season of the measurement. The lower thresholds are mainly determined by the surface albedo, but also include Rayleigh scattering. PMD algorithms therefore distinguish cloud free and cloudy pixels through intercomparison between cloudy and clear-sky topof-atmosphere radiances. The major advantage of the HICRU algorithm is the improvement of cloud retrieval through an iterative retrieval of thresholds, including image sequence analysis for the retrieval of the lower threshold. The algorithms for the retrieval of thresholds are described in Sect. 3.3 in detail. This make an accurate cloud retrieval also possible for regions like deserts, which often cause problems for other GOME cloud algorithms (Sect. 4).

\subsection{PMD detectors used for cloud retrieval}

HICRU can be applied to all PMD channels, but we choose to use the sum of the intensities of PMD2 (397-580 nm) and PMD3 (580-745 nm) for cloud retrieval because of the following considerations: The propagation of errors in the lower

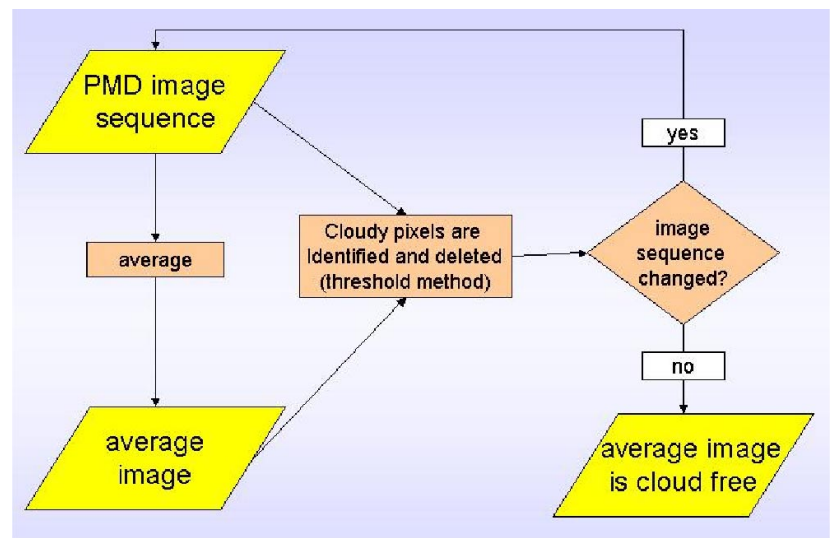

Fig. 2. Principle of the iterative fixpoint algorithm using image sequence analysis. HICRU uses this algorithm to calculate lower thresholds, which represent surface albedo.

thresholds to cloud fraction depends strongly on the intensity difference between the upper and the lower threshold. In desert regions, cloud fraction calculated from PMD3 is more sensitive to errors in the lower threshold than cloud fraction retrieved from PMD2, because the albedo of the desert is higher in the wavelength region covered by PMD3. Obviously it is the other way around for ocean. Hence the combined use of PMD2 and PMD3 was found to be a good compromise for different regions on earth. We should not switch between the used channels depending on surface albedo, because the obtained upper threshold and the instrument degradation also differ between the channels. Because of the strong degradation effects, in particular, for PMD1 (Aben et al., 2000; Krijger et al., 2005) this channel is omitted in HICRU. Further reasons for the exclusion of PMD1 are the strong sensitivity to the polarization of the earth radiance (Schutgens and Stammes, 2003) and the strong impact of Rayleigh-scattering in the UV-region covered by this detector. Therefore we also do not use color space analysis in HICRU, which is used additionally to the intensity-based approach by some of the existing cloud algorithms (e.g. the Optical Cloud Recognition Algorithm (OCRA, v. Bargen et al., 2000, and the Cloud Retrieval algorithm Using image Sequence Analysis, CRUSA, Wenig, 2001). The intensities of the three PMDs are interpreted as three different colors (red, green and blue) in the RGB colorspace by these algorithms. The main idea is the utilization of different color characteristics of clouds and the surface to distinguish cloud free and cloudy pixels more accurately. Nevertheless, we found that the retrieval is not predominantly limited by identification of cloud free pixels, but by the lack of measurements of cloud free scenarios (see also Krijger et al., 2006). 


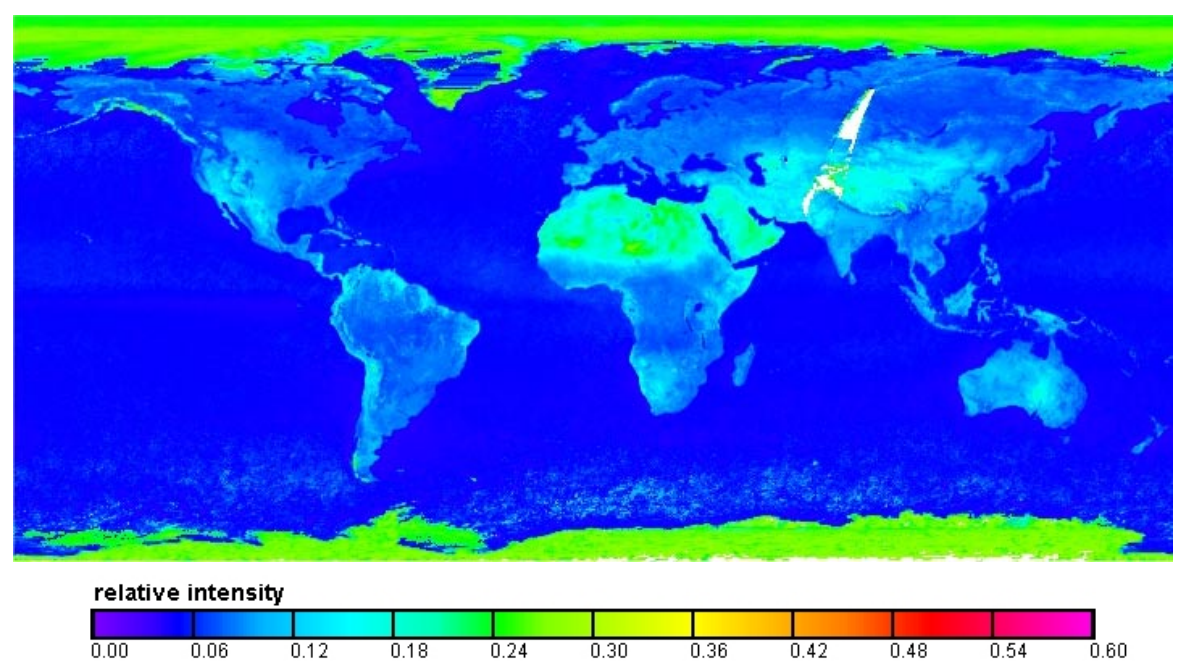

Fig. 3. The first approximation of the lower threshold retrieved by HICRU after stage 1 using all GOME data from 1996 to 2003 in subpixel 2 (west). There is lack of data in Asia close to Pakistan which refer to lack of measurements due to the unavailability of the ERS-2 tape recorder once per day exactly at that spot.

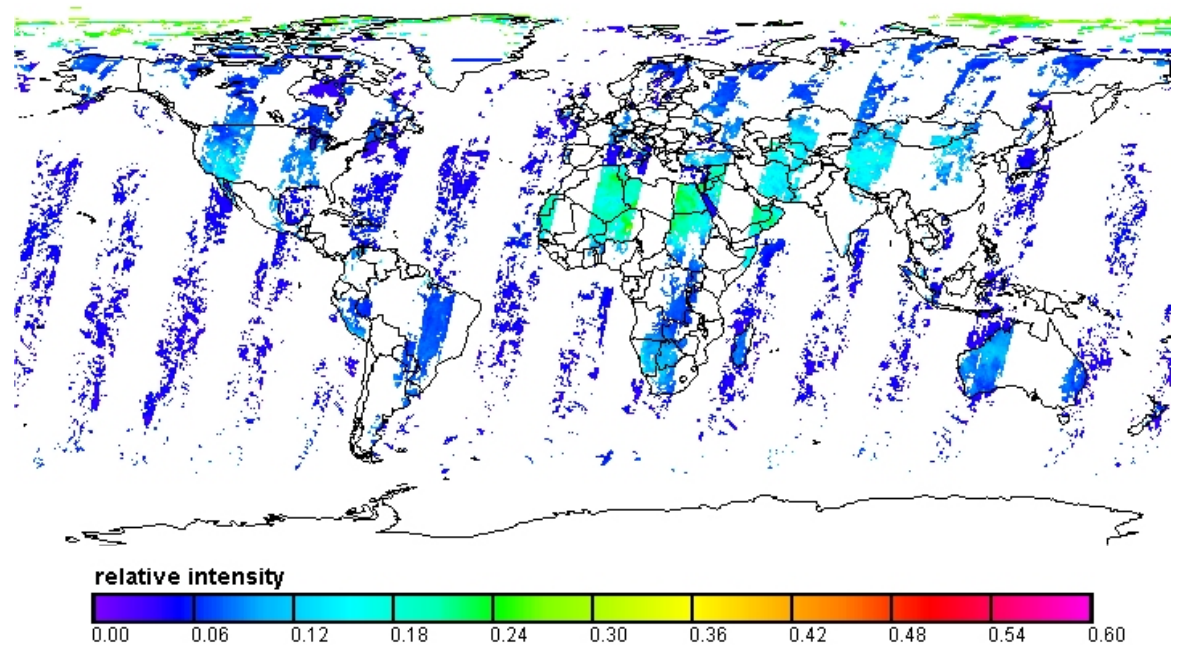

Fig. 4. Cloud free image after stage 4 for 1 day in subpixel 2 (west). The image contains a lot of gaps: In this case no cloud free measurement was available during the 25 days of measurement used for the retrieval during stage 4 and the results from the earlier stages are used.

\subsection{Retrieval of HICRU thresholds}

\subsubsection{Thresholds for cloud free pixels}

The lower threshold strongly depends on surface albedo and has to be calculated with respect to the latitude and longitude of measurement. We have to retrieve a map of the earth containing minimum reflectances of the sum of PMD2 and PMD3 as lower thresholds. Two different strategies could be applied: on the one hand, we should use short periods of time for the retrieval, because of seasonal variations of the surface albedo and the effects of irregular instrument degradation dependent on the time of measurement. Hence we should aim to retrieve maps representing the lower threshold separately for each day using periods as short as possible (HICRU uses 25 days). On the other hand, this method would only work appropriately if cloud free pixels exist during the considered period of time. This assumption holds well for regions like the Sahara, but is hardly acceptable for regions with persistent or seasonal cloud coverage. Note, that GOME needs three days to cover the earth completely, thus there are not more than 9 measurements during 25 days for some regions on earth and the possibility that all of them are cloudy is not negligible. To take both strategies into account, HICRU uses a four stage classification scheme analyzing both long and short periods of time (see Table 1). It is particularly 
Table 1. HICRU uses four stages for the retrieval of the lower threshold. Stage one retrieves only one image per subpixel (including backscan) using the whole period of time, stage 4 retrieves separate thresholds for each day. The number of images received as lower thresholds increase from stage to stage.

\begin{tabular}{ccl}
\hline stage & result & time period \\
\hline 1 & 4 images & Jan 1996-July 2003 (whole time) \\
2 & 16 images & Jan 1996-July 2003 (4 seasons) \\
3 & 124 images & $\begin{array}{l}\text { 4 seasons (separate for each year) } \\
\text { daily thresholds (using 25 days: 12 days } \\
\text { before and 12 days after the threshold is } \\
\text { calculated for) }\end{array}$ \\
& &
\end{tabular}

interesting to note that the reflectance of the PMDs depends systematically on the GOME subpixel. Hence we retrieve the thresholds separately for the four subpixels of GOME.

HICRU uses an iterative algorithm similar to CRUSA (Wenig, 2001) based on image sequence analysis for all four stages of threshold retrieval. The main idea is to retrieve accumulation points of low intensities instead of the absolute minimum during the considered period of time. This approach has at least three advantages: First the algorithm is more robust against errors in level- 1 data, especially if long periods of time are considered, because the result is not determined by one measurement alone. Moreover, the accumulation point method can take the seasonal variation of the albedo during the considered period of time into account, if there exist more than one measurement corresponding to cloud free pixels: the average of the intensities for cloud free scenarios is a better choice than the absolute minimum in this case. The third advantage is, that the minimum reflectance retrieved by an accumulation point method during long periods can be used as a pre-classification criterion for the analysis of short periods of time: Using long periods, we can identify all clouds which raise the intensity steeply to distinguish them from a variation of the surface albedo during the considered period of time. The assumed maximum variation of the surface albedo is pre-defined.

The principle of the iterative fixpoint algorithm is shown in Fig. 2. The algorithm is initialized by building up a set of daily global images containing the sum of the reflectances from PMD2 and PMD3, whereas all pixels with intensities clearly brighter than the Sahara are skipped. Each point of the image is then compared to the average image retrieved from the whole sequence. If the intensity of a measurement exceeds the sum of the average value and a pre-defined threshold (see Table 2), the measurement is interpreted as cloudy and skipped from the sequence. The result is an image sequence containing less clouds. This sequence is used as input to run the algorithm again. This is repeated until the image sequence does not change anymore. During stage 1 , this algorithm is applied to the whole data set of GOME measurements from 1996 to 2003. The result is used as input
Table 2. Technical parameters used for the iterative algorithm to retrieve the lower thresholds. The thresholds are determined manually based on time series of PMD intensities and case studies to take the expected maximum change in the surface albedo and changes in the instruments characteristics into account. For the effects of instrument degradation (and the lack of solar spectra for some months in 2001/2002) errors up to $8 \%$ are assumed for stage 1 based on time series.

\begin{tabular}{lll}
\hline stage & relative threshold & absolute threshold \\
\hline stage 1 & 0.23 & 0.075 \\
stage 2 & 0.16 & 0.075 \\
stage 3 & 0.08 & - \\
stage 4 & 0.035 & - \\
\hline
\end{tabular}

for the second stage and the average of this image sequence (Fig. 3) can be interpreted as first approximation of the lower threshold. During stage 2, 3 and 4 the algorithm is applied to gradually smaller sets of GOME data (see Table 1). After the fourth stage we obtain individual thresholds for each day, given by the average of the 25 days considered. An example for subpixel 2 is shown in Fig. 4. This image contains several gaps corresponding to points, where no cloud free pixel is found during the 25 days $^{1}$ (i.e., no value is left in the final image sequence). In this case, the algorithm has to use the average of the image sequences obtained from the earlier stages. Figure 4 shows, that stage 4 can be used over deserts, but not for most other regions on earth. On the other hand, errors in the retrieved albedo lead to errors in cloud fraction, especially for deserts, because of the high albedo in the wavelength region used by HICRU. This makes higher precision over deserts useful. Nevertheless, HICRU uses the stage covering the shortest period of time that includes cloud free pixels (spatial resolution of the threshold images: $0.5 \cdot 0.5$ degree).

\subsubsection{Thresholds for cloudy pixels}

The upper threshold represents a completely cloudy pixel for a cloud with high albedo. Image sequence analysis is not necessary for the retrieval, because the thresholds do not depend on surface albedo. Therefore we retrieve the upper threshold dependent on solar zenith angle and GOME subpixel only. The algorithm works similar to the retrieval of the lower threshold (Fig. 2), but is applied separately to 1024 different data sets of PMD-measurements: Each data set covers PMD-measurements for a solar zenith angle bin of 2 degree (overall 32 bins). Separate data sets are used for each year of GOME data and the four subpixels of GOME. The algorithm starts with all PMD-measurements from one of these data

\footnotetext{
${ }^{1}$ In practice, only 9 days of data are considered, because the earth is covered completely by GOME every three days only. During a time period of 25 days data is therefore available for 9 days only.
} 


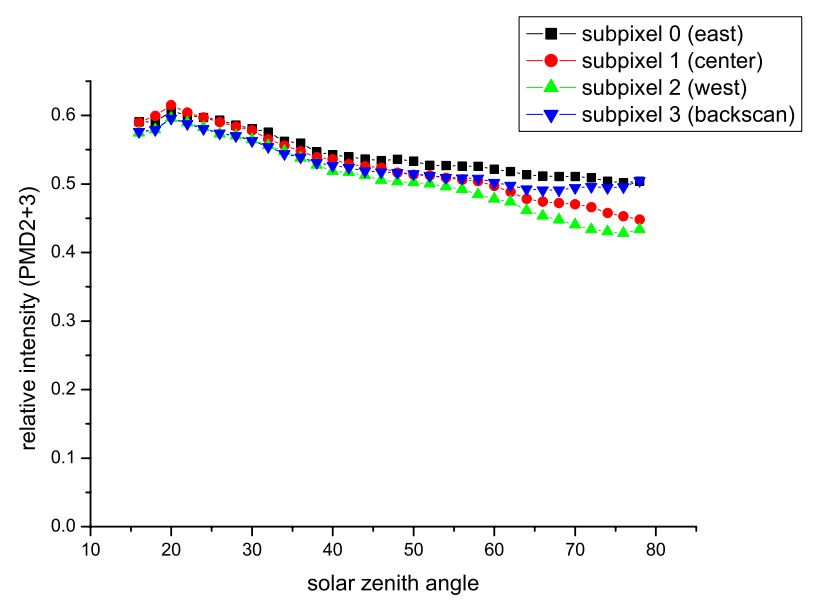

Fig. 5. The upper thresholds represent completely cloudy pixels. We found a clear dependency of the thresholds both on solar zenith angle and GOME subpixel.

sets, whereas pixels definitely not representing completely cloudy pixels are skipped through a threshold method used for pre-classification. Afterwards, each measurement of the data set is compared with the average of all measurements. If a measurement underestimates the average of all measurements by more than predefined absolute and relative thresholds (see Table 3), it is removed from the data set. The result is a reduced list of PMD measurements, which are used to run the algorithm again. This is repeated until the list does not change anymore. The results show a significant dependency of the retrieved thresholds on both solar zenith angle and subpixel (Fig. 5).

The choice of the algorithm's tuning parameters have to be selected carefully to obtain a smooth correlation between the upper threshold and the solar zenith angle without outliers due to events of single, bright measurements from clouds or ice surfaces. We use huge data sets (a whole year) in order to be mostly independent of climatological dependencies and robust to errors in the PMD data. A single measurement with very high intensity should hardly affect the result. The upper threshold represents completely cloudy pixels with a high, but not maximum or explicitly defined or retrieved albedo. Clouds with higher albedo than the "model cloud" represented by the upper threshold are interpreted as cloud fractions higher than 1 by HICRU.

Ice and snow covered surfaces can be brighter than clouds with high albedo. For the retrieval of the upper thresholds different, pre-defined regions usually covered by snow or ice are skipped.
Table 3. Technical parameters used for the iterative algorithm to retrieve the upper thresholds. At the beginning, all measurements with relative intensities lower than 0.40 are skipped. The table gives the parameters used for the iterations.

\begin{tabular}{ll}
\hline relative threshold & absolute threshold \\
\hline 0.07 & 0.05 \\
\hline
\end{tabular}

\section{Intercomparison of HICRU to other cloud algorithms}

New cloud algorithms have to be validated through intercomparison with existing cloud datasets. These intercomparisons have to be done carefully especially for effective cloud fractions, because most data sets retrieved from other satellite platforms or surface observations do not provide an effective cloud fraction as defined for GOME cloud algorithms, but a cloud coverage retrieved with other assumptions on different cloud properties. Hence the GOME cloud fractions retrieved from HICRU and other cloud algorithms cannot be compared directly to, e.g., ISCCP (Schiffer and Rossow, 1983) or to meteorological cloud coverage from surface observation. HICRU can be compared to other GOME cloud algorithms or one of the few other cloud products from other satellites retrieving effective cloud fractions. Nevertheless, this paper concentrates on the intercomparison between different cloud algorithms for GOME and the different approaches of the algorithms are discussed with respect to the results. For some of the cloud algorithms analyzed in this paper, intercomparisons are also discussed in Tuinder et al. (2004).

\subsection{Description of other cloud algorithms}

All GOME cloud algorithms retrieve effective cloud fraction and in some cases additional cloud parameters like cloud top height (see Sect. 1). From a technical point of view, two different methods are used for the retrieval of cloud fraction. The first method is the threshold method (see Sect. 3.1), which is used by the PMD algorithms. For the intercomparison with HICRU, we included several PMD algorithms with different implementations of the threshold method, which lead to significant differences between the algorithms (Table 4). The second method is applied to the channels with moderate spectral and lower spatial resolution and is used to retrieve cloud fractions by ICFA and FRESCO. While the threshold method is founded completely on an empirical base, the latter approach makes use of a radiative transfer model. Cloud fraction and, in the case of FRESCO, also cloud top height are retrieved using a $\chi^{2}$-minimization between the measured and the modelled spectra in and around the $\mathrm{O}_{2}$-A-Band. The GOME pixel of $320 \times 40 \mathrm{~km}$ is artificially divided into a cloud free and a cloudy part, where for the cloudy part a constant albedo is assumed a priori 
Table 4. Characteristics of the PMD cloud algorithms for GOME. Abbreviations: $1=$ lower threshold, $\mathrm{u}=$ upper threshold, $\mathrm{i}=$ interpolation between the thresholds.

\begin{tabular}{|c|c|c|c|c|c|c|c|c|c|}
\hline PMD algorithm & $\begin{array}{l}\text { used } \\
\text { PMDs }\end{array}$ & $\begin{array}{l}\text { number } \\
\text { of maps } \\
\text { (1) }\end{array}$ & $\begin{array}{l}\text { subpixel } \\
\text { correc- } \\
\text { tion }\end{array}$ & $\begin{array}{l}\text { color } \\
\text { space }^{\mathrm{a}}\end{array}$ & $\begin{array}{l}\text { iterative } \\
\text { re- } \\
\text { trieval }\end{array}$ & $\begin{array}{l}\text { Retrieval of } \\
\text { the upper } \\
\text { threshold }\end{array}$ & $\begin{array}{l}\text { Manipulation of } \\
\text { the thresholds after } \\
\text { their retrieval }\end{array}$ & $\begin{array}{l}\text { reduced } \\
\text { scale }^{b}\end{array}$ & References \\
\hline HICRU & 2,3 & $\begin{array}{l}4 \quad- \\
10444^{\mathrm{c}}\end{array}$ & empirical & - & $1, \mathrm{u}$ & $\begin{array}{l}\text { dependent } \\
\text { on sza and } \\
\text { subpixel }\end{array}$ & - & no & $\begin{array}{l}\text { further reference } \\
\text { (SCIAMACHY): } \\
\text { (Grzegorski et al., } \\
\text { 2004) }\end{array}$ \\
\hline OCRA/ROCINN & $1,2,3$ & $4^{\mathrm{d}}$ & analytical $^{\mathrm{e}}$ & $1, \mathrm{u}$ & - & $\begin{array}{l}\text { white point in } \\
\text { the RGB color } \\
\text { space }\end{array}$ & $\begin{array}{l}\text { lower and upper } \\
\text { threshold corrected } \\
\text { by OCRA scaling } \\
\text { factors }\end{array}$ & yes & $\begin{array}{ll}\text { Loyola } & (1998), \\
\text { v. Bargen } & \text { et al. } \\
(2000), & \text { Loyola } \\
(2004) & \end{array}$ \\
\hline $\begin{array}{l}\text { GOMECAT/PCRA }^{\mathrm{f}} \\
\mathrm{g}\end{array}$ & $1,2,3$ & $36^{\mathrm{h}}$ & - & - & 1 & $\begin{array}{l}\text { one value per } \\
\text { PMD channel } \\
\text { globally }\end{array}$ & $\begin{array}{l}\text { lower threshold } \\
\text { increased by } 10 \% \\
\text { globally, upper } \\
\text { threshold decreased } \\
\text { by } 10 \% \text { globally }\end{array}$ & yes & $\begin{array}{l}\text { Kurosu et al. (1998), } \\
\text { Kurosu et al. (1999), } \\
\text { v. Bargen et al. } \\
(2000)\end{array}$ \\
\hline $\begin{array}{l}\text { GOMECAT } \\
(\text { ISCCP })^{g}\end{array}$ & $1,2,3$ & $36^{\mathrm{h}}$ & - & - & 1 & $\begin{array}{l}\text { one value per } \\
\text { PMD channel } \\
\text { globally }\end{array}$ & $\begin{array}{l}\text { lower threshold } \\
\text { increased by } 5 \% \\
\text { globally, upper } \\
\text { threshold decreased } \\
\text { by } 45 \% \text { globallyg }\end{array}$ & yes & $\begin{array}{l}\text { (T. Kurosu, private } \\
\text { communication) } \\
\text { and references of } \\
\text { GOMECAT/PCRA }\end{array}$ \\
\hline CRUSA $^{\mathrm{i}}$ & $1,2,3$ & $\begin{array}{l}1+ \\
\text { subsets } \\
\mathrm{j}\end{array}$ & - & $1, \mathrm{u}, \mathrm{i}^{\mathrm{k}}$ & $1, \mathrm{u}$ & $\begin{array}{l}\text { one global } \\
\text { map } \\
(+ \text { subsets })^{\mathrm{j}}\end{array}$ & - & no & $\begin{array}{l}\text { Wenig et al. (1999), } \\
\text { Wenig and Leue } \\
(2000), \quad \text { Wenig } \\
(2001)\end{array}$ \\
\hline $\begin{array}{l}\text { PMD } \\
\text { algorithm }\end{array}$ & 2,3 & $\operatorname{subsets}^{\mathrm{j}}$ & - & - & $1, \mathrm{u}$ & $\begin{array}{l}\text { one global } \\
\text { map }\end{array}$ & - & no & - \\
\hline
\end{tabular}

a The usage of color space analysis by the algorithm. No color space analysis means, that the reflectances of the PMDs are used directly.

b A possible, artificial limitation of the retrieved cloud fractions to [0,1], because the cloud fraction is set to 1 , if the measured intensity exceeds the upper threshold and the cloud fraction is set to 0 , if the measured intensity is lower than the lower threshold.

c Dependent on the used HICRU stage.

d 4 maps with the lower thresholds for spring, summer, autumn and winter. Each map is based on three month of GOME data in April, July, October, January using three different years of GOME data respectively.

e The reflectances are divided by the cosine of the line of sight angle. This correction strongly deviates from the results retrieved by HICRU.

${ }^{\mathrm{f}}$ GOMECAT is an improved version of the PCRA algorithm. The algorithm differs from PCRA as described in v. Bargen et al. (2000) in its retrieval of the upper threshold. Furthermore, the relation of PMD2 and PMD3 is no more used (T. Kurosu, private communication).

$\mathrm{g}$ GOMECAT and GOMECAT(ISCCP) are the the same algorithms, but the thresholds are manipulated in different ways after their retrieval. GOMECAT(ISCCP) use one month of the cloud coverage from ISCCP cloud climatology (Schiffer and Rossow, 1983) and changes the upper and the lower threshold by a global, constant factor each to receive the smallest difference between GOMECAT(ISCCP) and the ISCCP climatology.

$\mathrm{h}$ Thresholds separately for the 12 months of the year and for the three PMD channels. All available GOME data is used for the retrieval of the thresholds.

$\mathrm{i}$ The CRUSA release used for the intercomparisons include some changes with respect to the references: the plotting routine is changed and the cloud fraction is retrieved for every GOME measurement using the thresholds from the images. The CRUSA release described in the references is completely based on image sequence analysis and provides images of daily cloud fraction only.

$\mathrm{j}$ The algorithm works similar to stage 1 of the algorithm used in HICRU for the retrieval of the lower thresholds. The image received as lower threshold is the average of an image sequence. Subsets of this image sequence are used to take seasonal variations partly into account. $\mathrm{k}$ The cloud fraction is retrieved through a two dimensional, linear interpolation in a HSV subspace. The cloud fraction depends on the brightness and the saturation in the color space. The hue is neglected.

${ }^{1}$ This is a test algorithm implemented by the developers of HICRU for test purposes only. Lower thresholds are retrieved similar to stage 1 of HICRU, but only based on the year 1997. Subsets of the final image sequence are used to take seasonal variations partly into account (similar to CRUSA). Upper thresholds are retrieved in the same way as the lower thresholds, but a maximum is retrieved instead of a minimum. 
Table 5. Results of the linear fit of the cloud fraction: $X_{c f}(C A)=m \cdot X_{c f}(\mathrm{HICRU})+\mathrm{b}$ between HICRU and various other GOME cloud algorithms (CA) for orbit 70716086 (16 July 1997). The table contains the correlation coefficient $\mathrm{R}$ and the standard deviation SD. Beside the PMD test algorithm (a algorithm implemented by the HICRU developers for test purposes and interpretation of the data) the best correlation is found for HICRU and GOMECAT.

\begin{tabular}{ccccc}
\hline Algorithm (CA) & $\mathrm{R}$ & $\mathrm{SD}$ & $\mathrm{b}$ & $\mathrm{m}$ \\
\hline FRESCO (GO-v3) & 0.9163 & 0.0889 & 0.0814 & 0.9838 \\
ICFA & 0.8581 & 0.1259 & -0.0090 & 1.0647 \\
OCRA & 0.9386 & 0.1225 & 0.0583 & 1.6118 \\
GOMECAT & 0.9760 & 0.0498 & 0.0128 & 1.0809 \\
CRUSA & 0.9234 & 0.1105 & -0.0654 & 1.2855 \\
GOMECAT(ISCCP) & 0.9227 & 0.1260 & 0.1542 & 1.4577 \\
FRESCO old (GO-v1) & 0.8287 & 0.1246 & 0.1489 & 0.8917 \\
PMD test algorithm & 0.9869 & 0.0328 & -0.0054 & 0.9704 \\
\hline
\end{tabular}

(FRESCO: 80\%). For radiative transfer modelling, a lambertian cloud is assumed and Rayleigh scattering is neglected.

The definition of cloud fraction in FRESCO is quite similar to the concept used by HICRU and the other PMD algorithms: both algorithms retrieve an effective, intensity-based cloud fraction with respect to a cloud with high albedo. But while this cloud albedo is arbitrarily set to $80 \%$ by FRESCO, it is assumed indirectly for HICRU by retrieving the upper threshold. For this reason, it is especially interesting to compare the results from HICRU with FRESCO, because on the one hand, both types of algorithms use a similar concept of effective cloud fraction, but on the other hand, different detectors on the same satellite instruments and completely different retrieval algorithms are used. Furthermore, FRESCO is an established and well validated algorithm (e.g. Koelemeijer and Stammes, 2000; Koelemeijer et al., 2002). Besides the intercomparison for one orbit including all described cloud algorithms (Sect. 4.2), we also include a detailed intercomparison between HICRU and FRESCO using one month of GOME data (Sect. 4.3). During the development of this paper a new version of the FRESCO algorithm (FRESCO GO-v3, see also Fournier et al., 2006) has become available, which makes use of a better surface albedo database (Koelemeijer et al., 2003) and uses an improved calibration of the spectral data compared to the old version (FRESCO GO-v1). We use the new database, but include both FRESCO versions for some of the studies.

\subsection{Correlation of HICRU with other cloud algorithms for GOME orbit 70716086}

We analyzed the representative orbit 70716086 (16 July 1997) with respect to the results from HICRU and all the other algorithms described above. The orbit covers different kinds of surfaces: ocean, rain forest in central Africa, the
Sahara and East Europe. We found, that overall the cloud fraction is described in a similar way by all cloud algorithms (Fig. 6). But also substantial differences are found. These are analyzed in detail in the following subsections.

\subsubsection{General differences between the algorithms}

We correlated the results of all algorithms to those of HICRU. The highest correlation coefficient (0.987) and the smallest standard deviation (0.033) is found for the PMD test algorithm, which was implemented by the HICRU developers to constitute the design of HICRU (see Table 4) and is included in the intercomparison to support the interpretation of the data. Although there is strong correlation between HICRU and the more simple test algorithm, the improvement of HICRU for the retrieval of cloud free pixels can be seen directly from the correlation: The significant reduction of negative cloud fractions is an improvement in the cloud retrieval, because both algorithms use an accumulation point method for the retrieval of the thresholds. The cloud fraction becomes negative, if the measured intensity is smaller than the lower threshold. Note, that only the CRUSA algorithm plots negative cloud fractions beside HICRU and the PMD test algorithm, whereas the other PMD-algorithms artificially set the cloud fraction to 0 , if the measured intensity is less than the lower threshold.

A similar high correlation as for the PMD test algorithm is also found for GOMECAT (0.976, see Table 5). For both algorithms the correlation to HICRU is significantly higher than for the others $(<0.94)$.

We found a correlation coefficient lower than 0.9 for only two of the analyzed algorithms: ICFA (0.867) and the old FRESCO version (0.828). For the old FRESCO version (FRESCO GO-v1) albedo information is retrieved using two months of GOME data only, which is a smaller data set compared to the retrieval of the lower threshold by all PMD algorithms. The seasonal variation of surface albedo is not taken into account. The new FRESCO version (FRESCO GO-v3) uses the database (Koelemeijer et al., 2003), which retrieves monthly albedo maps based on 5 months of GOME data each. Because of the higher correlation coefficient for the new FRESCO version (0.916), we ascribe the relatively low correlation coefficient of the old version to the shortcomings of the old FRESCO version compared to the new one. The correlations of both FRESCO versions to HICRU are significantly higher $(0.921 / 0.964)$ if desert regions are neglected. This is explained in Sect. 4.2.3. The relatively low correlation of ICFA with HICRU is ascribed to the well-known shortcomings of the ICFA algorithm (Sect. 1).

For OCRA, GOMECAT(ISCCP), CRUSA and FRESCO we found a correlation coefficient between 0.91 and 0.94 . Note, that the standard deviation of the linear fit is significantly lower (0.089) for FRESCO than for the correlation of the three other algorithms with HICRU. Nevertheless, these four algorithms mainly differ qualitatively from HICRU for 

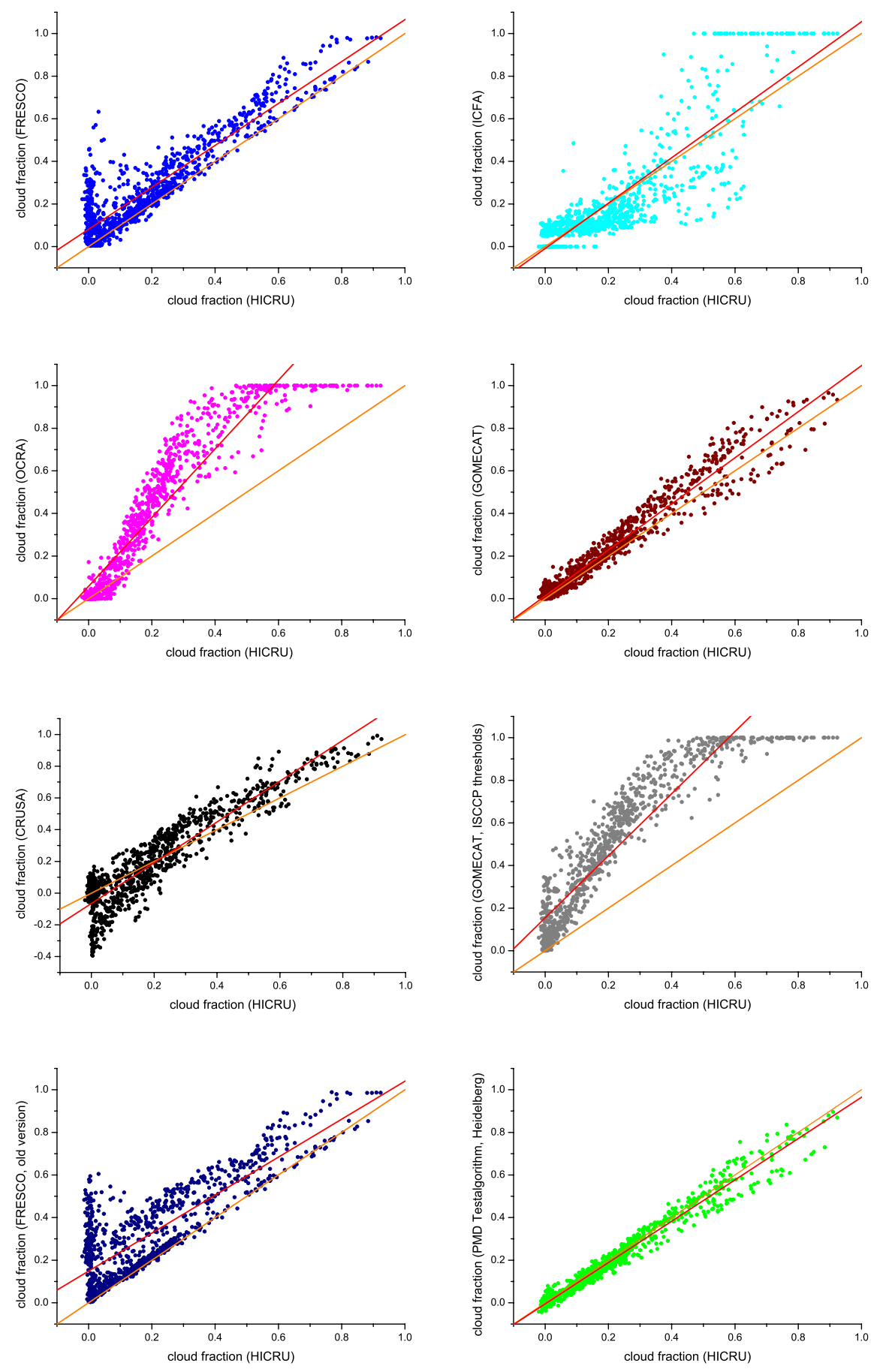

Fig. 6. Correlation between HICRU and several other GOME cloud algorithms for orbit 70716086 (16 July 1997; latitude range: -55 - 65 degree) plotted together with the linear fit (red) and the identity function (orange). Note, that the y-scale of CRUSA deviates from the other algorithms.

very high or very low cloud fractions. CRUSA sometimes retrieves negative cloud fractions (typically between 0.0 and -0.2 , sometimes up to -0.4) for HICRU cloud fractions lower than 0.15 . This problem is due to inappropriate assump- tions for the interpolation between the lower and the upper threshold in HSV-color space, which results in difficulties for regions with high saturation values of the lower threshold (especially over ocean). This problem of CRUSA is 

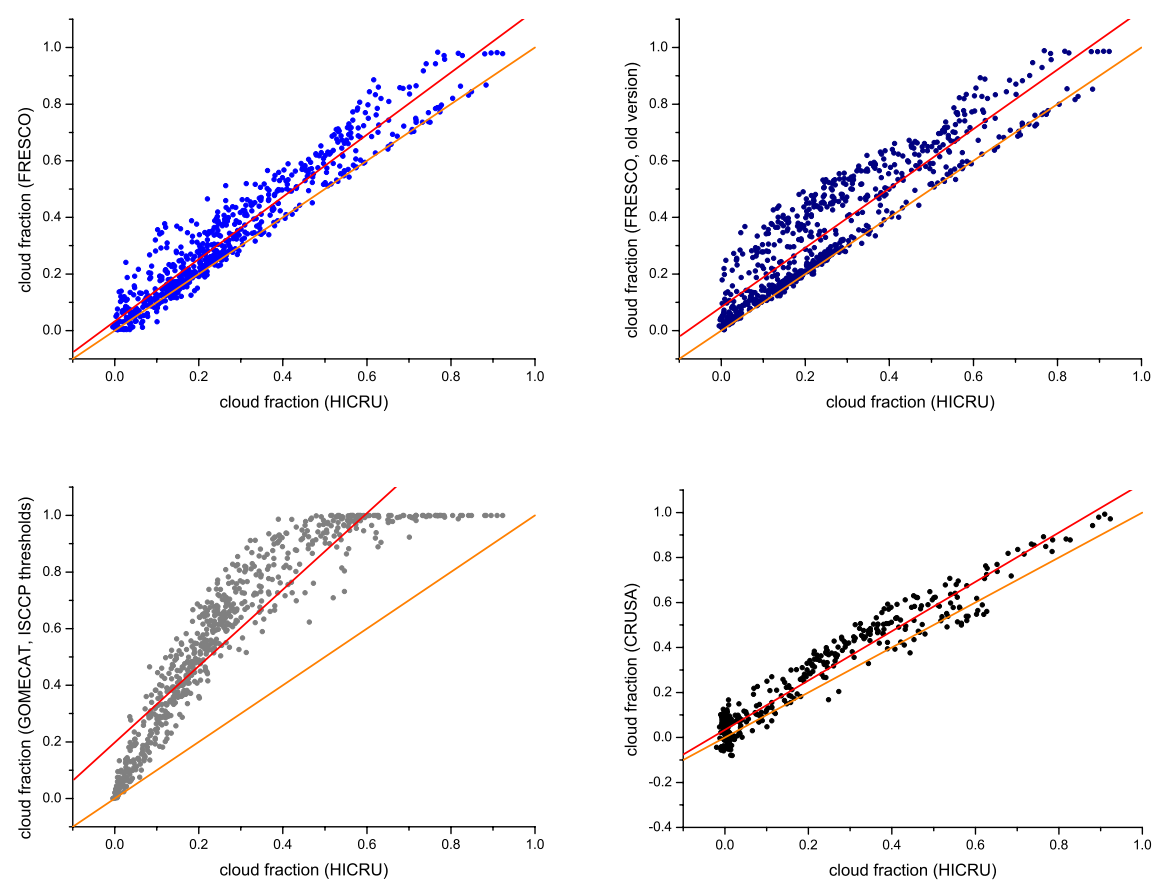

Fig. 7. Correlation between HICRU and other GOME cloud algorithms for orbit 70716086 (16 July 1997). The two FRESCO releases and GOMECAT(ISCCP) are plotted without the pixels over Sahara and Namib desert (latitude range: 12-22 and -25-12 degree). The CRUSA data is plotted without the parts of the orbit completely or partly covered with ocean (latitude range $-55-(-3)$ degree, 30-47 degree, $>59$ degree). Excluding these regions with particular problems for the four algorithms, the agreement with HICRU is significantly improved for small cloud fractions. The linear fit is shown in red, the identity function is plotted in orange.
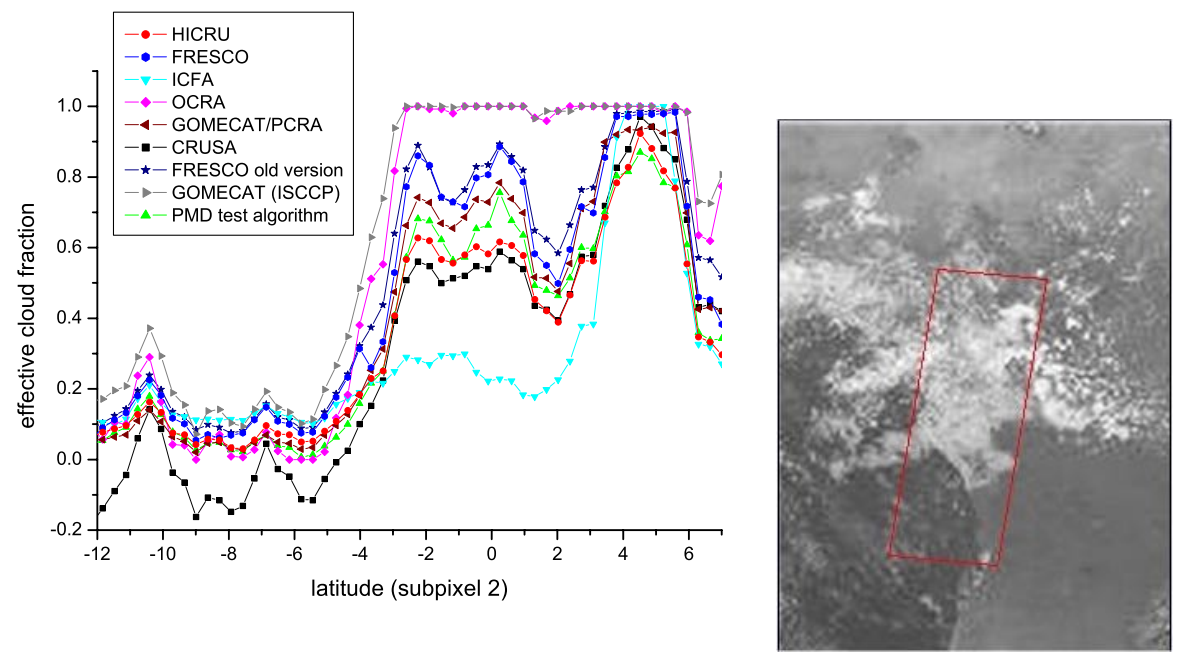

Fig. 8. Case study: Intercomparison between HICRU and other cloud algorithms over rain forest and ocean (orbit 70716086). The satellite image from Meteosat (taken from http://www.eumetsat.de, copyright @2005 EUMETSAT), retrieved 1.5 h after the GOME measurement, show clouds with varying albedo, which should be represented by a varying effective cloud fraction.

significantly improved, if regions completely or partly covered by ocean are neglected (Fig. 7). OCRA and GOMECAT(ISCCP) retrieve significant higher cloud fractions than
HICRU, but with a good correlation for a wide range of cloud fractions. But HICRU cloud fractions between 0.5 and 1.0 are often interpreted as a cloud fraction of 1.0 by 

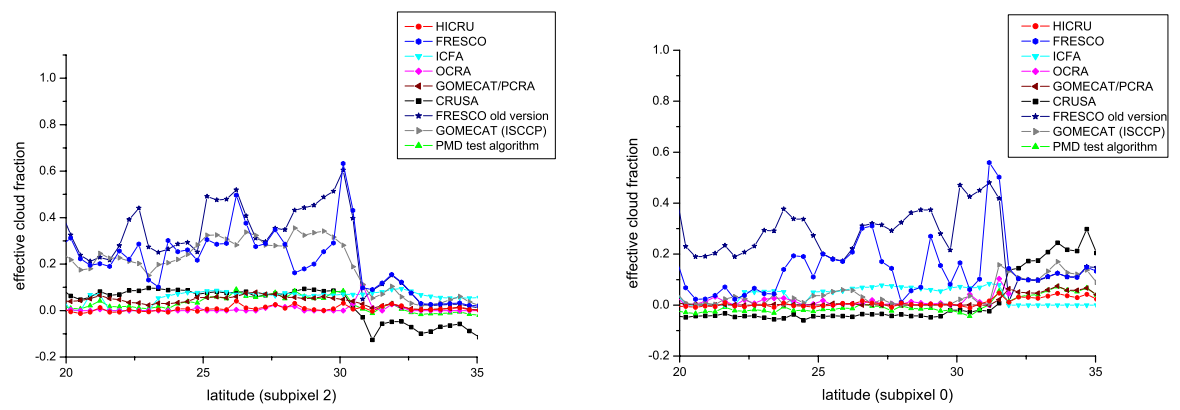

Fig. 9. Intercomparison between HICRU and other cloud algorithms for a cloud free scenario over Sahara both for subpixel 0 (east) and subpixel 2 (west). Especially FRESCO and GOMECAT (ISCCP) overestimate effective cloud fraction over Sahara. The overestimation of cloud fraction over Sahara is greater in subpixel 2 than in subpixel 0.
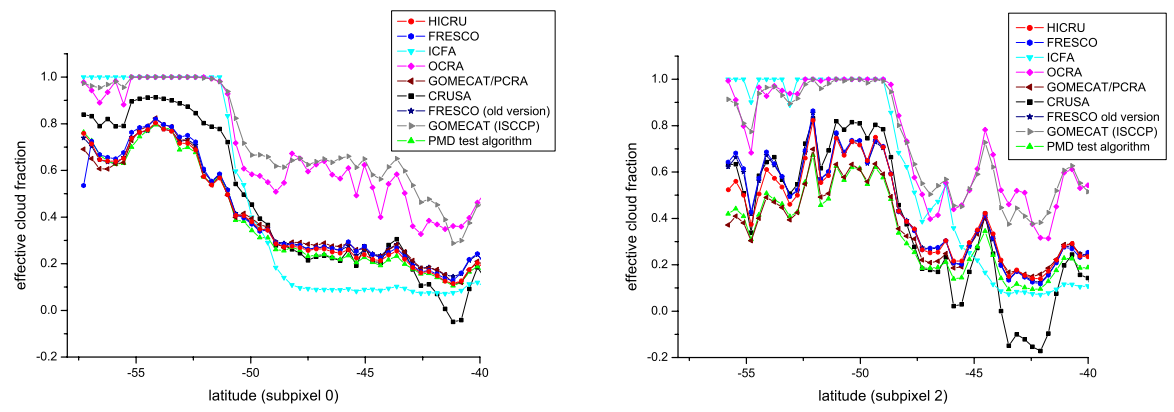

Fig. 10. Intercomparison between HICRU and other GOME cloud algorithms over ocean for high solar zenith angles. HICRU, FRESCO, GOMECAT and the PMD test algorithm agree very well with each other in subpixel 0 (east). In subpixel 2 (west), FRESCO agrees with HICRU, while GOMECAT and the PMD test algorithm retrieve lower values than HICRU, because the subpixel dependency of the upper threshold is not taken into account.

these algorithms. On the other hand, FRESCO and GOMECAT(ISCCP) retrieve a wide range of cloud fractions (between 0.0 and 0.4 ) in the case of vanishing HICRU cloud fraction. These differences of the three algorithms to HICRU can be explained by analyzing two case studies (Sects. 4.2.2 and 4.2.3).

\subsubsection{Case study over Central Africa}

The first case study covering African rain forest and ocean demonstrates the importance of an appropriate definition of the upper threshold for PMD algorithms. Most algorithms describe this cloudy scenario qualitatively similar to HICRU. Three algorithms deviate: ICFA retrieves significantly lower cloud fractions than the other algorithms. OCRA and GOMECAT(ISCCP) retrieve cloud fractions with a nearly constant value of 1 for the latitude range from -3 degree to +6 degree. The corresponding Meteosat image (12:00 a.m.) shows a cloudy scenario. However, it now becomes important that an effective cloud fraction is sensitive both to cloud coverage and cloud albedo. HICRU and most other cloud algorithms correctly retrieve a varying cloud fraction, because of the varying albedo as seen on the Meteosat image. While
OCRA and GOMECAT(ISCCP) correlate with HICRU for a wide range, they cannot detect a variation of effective cloud fraction in the case of high cloud coverage with high cloud albedo, because the upper threshold refers to a quite low cloud albedo and the cloud fraction is set to 1 if the measured intensity exceeds the upper threshold. Thus, information is lost in these two algorithms. Note, that GOMECAT and GOMECAT(ISCCP) refer to the same algorithm, but the lower and the upper threshold are manipulated after the retrieval in different ways (see Table 4), especially the upper threshold is decreased by $45 \%$ for GOMECAT(ISCCP) (T. Koruso, private communication).

\subsubsection{Case study over Sahara}

Figure 9 shows the results of all cloud algorithms in North Sahara including the border to the Mediterranean for subpixel 0 (east) and subpixel 2 (west). The scenario is proven to be cloud free over the Sahara using Meteosat images. GOMECAT(ISCCP) and the two FRESCO releases overestimate the cloud fraction over the Sahara. The cloud fraction decreases immediately at the border between the Mediterranean and the Sahara. The overestimation of cloud 
Table 6. Results of the linear fit $X_{c f}(\mathrm{FRESCO})=\mathrm{m} \cdot \mathrm{X}_{\mathrm{cf}}(\mathrm{HICRU})+\mathrm{b}$ for the correlations between HICRU and FRESCO shown in Fig. 11. The table contains the correlation coefficient $\mathrm{R}$, the standard deviation $\mathrm{SD}$ and the number of the included measurements $\mathrm{N}$.

\begin{tabular}{cccccc}
\hline region & $\mathrm{R}$ & $\mathrm{SD}$ & $\mathrm{N}$ & $\mathrm{b}$ & $\mathrm{m}$ \\
\hline pacific & 0.9931 & 0.0308 & 43900 & 0.0314 & 1.0678 \\
all & 0.9776 & 0.0530 & 307610 & 0.0455 & 1.0459 \\
\hline
\end{tabular}

fraction in desert regions by these three algorithms mainly explains the large differences with respect to HICRU for small cloud fractions (see Fig. 7). It is again interesting to analyze the difference between GOMECAT and GOMECAT(ISCCP). GOMECAT retrieves small cloud fractions between 0.0 and 0.1 over Sahara whereas GOMECAT(ISCCP) calculates values between 0.1 and 0.4 . This is due to the smaller increase of the retrieved lower threshold for GOMECAT(ISCCP) and especially to the strong decrease of the upper threshold compared to GOMECAT. Thus the intensity difference between the upper and the lower threshold is very small over the Sahara in GOMECAT(ISCCP), which makes the algorithm very sensitive to small errors. The overestimation of GOMECAT(ISCCP) and FRESCO is higher in subpixel 2 than in subpixel 0 in the considered case. This subpixel effect seems to be a general effect for FRESCO (and probably also for other algorithms): Analyzing all FRESCO measurements over central Sahara (latitude range 15-30 degree, longitude range 10-30 degree) for the corresponding month (July 1997), we found that only $3 \%$ of the cloud fractions retrieved by FRESCO in subpixel 2 are lower than 0.1, but $37.3 \%$ in subpixel 0 . For orbit 70716086 there is a similar effect for further algorithms: GOMECAT, CRUSA and the PMD test algorithm retrieve slightly enhanced cloud fractions in subpixel 2 (between 0.0 and 0.1). In subpixel 0, negative cloud fractions are retrieved by CRUSA and the PMD test algorithm. HICRU retrieves vanishing cloud fraction nearly exactly in both subpixels. Through intercomparison with the PMD test algorithm we conclude, that the subpixeldependent thresholds improve the results of the HICRU algorithm. Nevertheless, although HICRU works significantly better over desert than other cloud algorithms, we still expect errors of up to $2 \%$ from the analysis of a huge set of HICRU data. For the SCIAMACHY data product of FRESCO, a new release has been developed, which corrects for the effect of desert dust on the surface albedo database (Fournier et al., 2006).

Figure 9 shows, that GOMECAT retrieves a vanishing cloud fraction in subpixel 0 and OCRA small or vanishing cloud fractions for subpixel 0 and subpixel 2 . On the one hand, this could indicate an accurate retrieval of cloud fraction for these two algorithms. But on the other hand, we cannot distinguish between accurate and overestimated lower thresholds for these algorithms, because negative cloud fractions are set to 0 .

Generally we would expect to find negative cloud fractions in the GOMECAT and the OCRA dataset, if negative cloud fractions were not set to 0: the GOMECAT algorithm increases the lower thresholds by $10 \%$ after their retrieval, therefore the measured intensity should sometimes be lower than the used threshold. For OCRA, the selection of cloud free pixels depends on both the retrieved lower thresholds and pre-defined scaling factors, where one of the scaling factors can result in a similar effect as the increase of the lower threshold. Thus the lower thresholds of OCRA could be overestimated, which would explain, that in the case of vanishing OCRA cloud fractions, we found HICRU cloud fractions between 0.00 and 0.08 for the investigated orbit, which is a more extended range than for all other algorithms except ICFA and CRUSA with their known problems (Fig. 6). A further limitation of the OCRA algorithm is the quite limited set of GOME data used for the retrieval of the lower threshold (Table 4), which is according to our experience too small to find cloud free pixels in several cases.

\subsubsection{Case study over ocean: subpixel dependency for high solar zenith angles}

The case study (Fig. 10) shows measurements over ocean for high solar zenith angles. In subpixel 0 (east) we found a very precise agreement between FRESCO, GOMECAT, the PMD test algorithm and HICRU. On the other hand, only FRESCO agrees with HICRU precisely in subpixel 2 (west), whereas the PMD test algorithm retrieves lower values and agrees exactly with the GOMECAT algorithm. Therefore some of the aspects included in our subpixel-dependent retrieval of the upper threshold are obviously similarly described by the model used in FRESCO, which uses one representative line of sight angle for each subpixel of GOME.

\subsection{Detailed intercomparison between HICRU and FRESCO}

We performed a more comprehensive comparison between FRESCO and HICRU using all orbits in January 1997 because of the reasons discussed in Sect. 4.1. Only measurements between -50 degree and +50 degree latitude are included to avoid a strong influence of measurements over snow and ice covered surfaces on the results. Figure 11 and Table 6 show that the correlation is generally very good but the correlation over ocean is better than over land (correlation coefficient 0.993 and 0.978 ). Overall, the correlation between HICRU and FRESCO is significantly better for January 1997 compared to the orbit analyzed in Sect. 4.2. This can be easily understood, because the orbit 70716086 contains different kind of surfaces, but ocean is strongly underrepresented and desert is over-represented with respect to the global average. But the correlation between HICRU and 

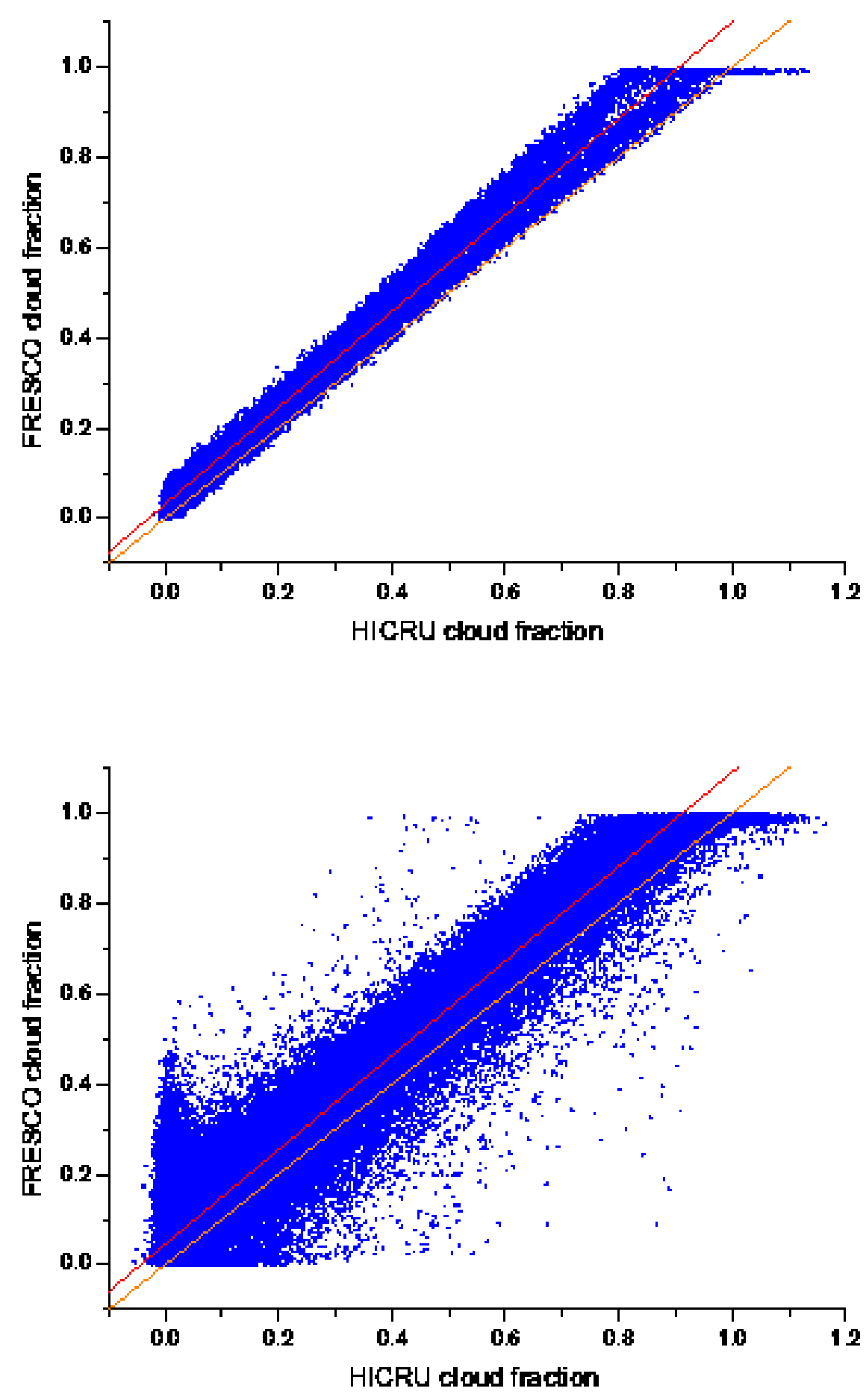

Fig. 11. Correlation between the cloud fraction retrieved by HICRU and FRESCO. We include measurements between -50 degree and +50 degree latitude only to exclude most pixels strongly influenced by ice and snow covered surfaces. The plots show all measurements during January 1997 (right) and the measurements over pacific ocean defined by the longitude range between -180 degree and -130 degree during January 1997 (left). The correlation is significant higher for pacific ocean. The linear fit is shown in red, the identity function is plotted in orange. 


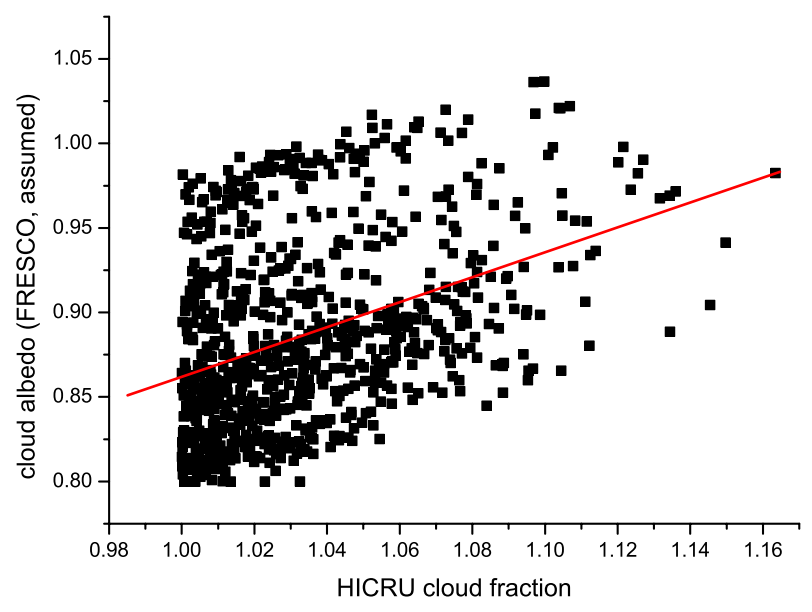

Fig. 12. The measurements referring to HICRU cloud fraction higher than 1 are weakly correlated to FRESCO cloud albedo. But if the intensity is higher than expected for a completely cloudy pixel with $80 \%$ albedo, FRESCO increases the cloud albedo to values higher than $80 \%$, which is usually fixed to $80 \%$ a priori. On the other hand, HICRU interprets completely cloudy pixel brighter than the upper thresholds as effective cloud fractions above 1 . This study contains all measurements in January 1997 for a latitude range of 50 degree and +50 degree. The linear fit is shown in red.

FRESCO is best over ocean and the results of FRESCO are wrong over desert. Therefore the different compositions of surfaces for the considered orbit compared to the global average can explain differences in the correlation coefficients.

Although there is generally a very good correlation between HICRU and FRESCO, there are also differences especially for very high and low cloud fractions. Differences for small cloud fractions are mainly due to differences between the surface albedo database used by FRESCO and the lower thresholds used by HICRU, because they are mainly found for pixels over land. The increased FRESCO cloud fractions in the case of vanishing HICRU cloud fractions are again due to the overestimation of FRESCO over deserts. We also found a relatively small set of measurements with enhanced cloud fractions of HICRU but small FRESCO cloud fractions (for $0.25 \%$ of the measurements we found HICRU cloud fractions $>0.08$ with corresponding FRESCO cloud fractions $<0.03)$. These differences are found over land only and we have not yet found a clear explanation.

FRESCO sometimes retrieves cloud fraction 1 for HICRU cloud fraction $>0.75$ and the HICRU cloud fractions are sometimes greater than 1 . This is partly due to different, but consistent concepts of effective cloud fraction. If the measured intensity exceeds the upper threshold, HICRU interprets the result as cloud fraction greater than 1, which can happen if the cloud albedo is higher than indirectly assumed by the upper threshold. In the same case, FRESCO fixes the cloud fraction close to 1 and increases the cloud albedo to values greater than $80 \%$. HICRU cloud fractions greater than 1.0 only weakly correlate with the cloud albedo of FRESCO (correlation coefficient 0.38), but we nevertheless usually found a FRESCO cloud albedo higher than $80 \%$ if the HICRU cloud fraction exceeds 1 (Fig. 12).

Overall, we found a very good correlation between HICRU and FRESCO and most differences are explained by the aspects discussed above. Nevertheless, the remaining differences seem to depend on the solar zenith angle, where a better agreement is found for higher solar zenith angles $(>40)$. These differences are under investigation and not completely understood.

\subsection{Shortcomings of HICRU and other cloud algorithms}

There are also shortcomings limiting the cloud retrieval of HICRU: For HICRU and the other cloud algorithms, cloud retrieval is impossible over ice and snow covered surfaces and in the case of sun glint. The cloud fraction is usually overestimated in these cases.

The intensities measured by the PMD instruments systematically depend on the subpixel of GOME. HICRU improves cloud retrieval by calculating subpixel-dependent thresholds. Some parts of this correction are similarly described by the model used in FRESCO. Nevertheless, there still remains a relatively small subpixel-dependency of the retrieved cloud fraction on GOME subpixel both for HICRU and FRESCO. These effects are not completely understood and under investigation in cooperation between University of Heidelberg and KNMI. The results will be published in a separate paper. The actual Bidirectional Reflectance Distribution Function (BRDF) can be a possible reason due to scattering properties of water and ice clouds for cloudy scenarios and perhaps also due to Rayleigh-scattering for clear sky pixels.

\section{Conclusions and outlook}

The HICRU algorithm improves the retrieval of cloud fractions from GOME PMD data using a sophisticated, iterative algorithm for the retrieval of the thresholds. Image sequence analysis is used for the calculation of the lower thresholds. HICRU uses PMD2 (397-580 nm) and PMD3 (580-745 nm) and improves the calculation through a subpixel-dependent retrieval of the thresholds.

The results of HICRU are compared to several other algorithms for GOME and discussed with respect to particular specificities of the algorithms. The new methods used for the retrieval of thresholds in HICRU significantly improves the results for small cloud fractions. The cloud fraction is generally described in a similar way by all algorithms. For most algorithms we found a correlation coefficient between 0.91 and 0.94 for the linear fit to HICRU (FRESCO (GO-v3), OCRA, GOMECAT(ISCCP), CRUSA). Apart from the PMD test algorithm (a test algorithm implemented by the HICRU developers to support the analysis of the data), the highest 
correlation is found for the GOMECAT algorithm (0.98). Correlations lower than 0.9 are found for ICFA $(0.86)$ and the old FRESCO-GO-v1 version (0.82), which can be explained by the shortcomings of these two algorithms: ICFA directly uses the absorption of oxygen for the retrieval of cloud fraction. The cloud top height is taken from climatology which can lead to large errors in cloud fraction if the cloud top height deviates from the climatological average. The old FRESCO version uses an inaccurate albedo database retrieved from two months of GOME data only. This is improved by the new FRESCO version (GO-v3).

The intercomparison between HICRU and FRESCO is particularly interesting, because both algorithms use a similar concept of effective cloud fraction, but different detectors and retrieval methods. We therefore compared both algorithms using all orbits in January 1997. We found overall a very good correlation between FRESCO and HICRU (0.978). The correlation over ocean (0.993) is higher than over land.

Over deserts, cloud fraction is overestimated by FRESCO and GOMECAT(ISCCP). This problem is averted by HICRU and the intercomparison over desert shows, that the methods used for HICRU also improve the results over desert compared to the other PMD algorithms.

The upper threshold of HICRU, retrieved as accumulation point of highest intensities, depends both on solar zenith angle and GOME subpixel. The different PMD based algorithms use different definitions of the upper threshold. OCRA and GOMECAT(ISCCP) retrieve an effective cloud fraction which seems to be inconsistent for high cloud fractions, because the upper threshold refers to a lower cloud albedo compared to HICRU and the cloud fraction is set to unity if the measured intensity exceeds the upper threshold. No more variations are detected for high effective cloud fractions by these algorithms.

HICRU is also applied to the SCIAMACHY instrument on ENVISAT-1. Although the SCIAMACHY retrieval is similar to the GOME algorithm presented in this paper, some changes are implemented with respect to the different instrument characteristics and possibilities of SCIAMACHY. The validation of the SCIAMACHY algorithm is in progress and will be presented in a forthcoming paper. First results are presented in (Grzegorski et al., 2004).

The HICRU data is available both for GOME and SCIAMACHY as database in ASCII format from the webpage of the satellite group at the University of Heidelberg (http: //satellite.iup.uni-heidelberg.de).

Future algorithms will retrieve cloud top height by combining HICRU cloud fraction with DOAS evaluation of $\mathrm{O}_{2}$ and $\mathrm{O}_{4}$ and radiative transfer modelling.

Acknowledgements. We are grateful to ESA and DLR for providing us with GOME level-1 data and ICFA cloud data, which is taken from the official level-2 dataproduct.
We strongly appreciate the TEMIS project for providing us with FRESCO data. The used FRESCO data were downloaded from the TEMIS webpage: http://www.temis.nl.

The Netherlands SCIAMACHY data center is acknowledged for making available cloud fractions retrieved by the old FRESCO version.

We are highly grateful to T. Kurosu for the retrieval of GOMECAT cloud data.

We are also very thankful to D. Loyola for providing us with OCRA cloud data.

Edited by: C. George

\section{References}

Aben, I., Eisinger, M., Hegels, E., Snel, R., and Tanzi, C.: GOME data quality improvement GDAQI final report, SRON and DLR and Alfred Wegener Institute and Institut fuer Fernerkundung, 2000.

Acarreta, J. R., de Haan, J. F., and Stammes, P.: Cloud pressure retrieval using the $\mathrm{O}_{2}-\mathrm{O}_{2}$ absorption band at $477 \mathrm{~nm}$, J. Geophys. Res., 109(D5),D05204, doi:10.1029/2003JD003915, 2004.

Beirle, S., Platt, U., von Glasow, R., Wenig, M., and Wagner, T.: Estimate of nitrogen oxide emissions from shipping by satellite remote sensing, Geophys. Res. Lett., 31, L18103, doi:10.1029/2004GL020312, 2004a.

Beirle, S., Platt, U., Wenig, M., and Wagner, T.: Highly resolved global distribution of tropospheric $\mathrm{NO}_{2}$ using GOME narrow swath mode data, Atmos. Chem. Phys., 4, 1913-1924, 2004b.

Beirle, S., Platt, U., Wenig, M., and Wagner, T.: Weekly cycle of $\mathrm{NO}_{2}$ by GOME measurements: A signature of anthropogenic sources, Atmos. Chem. Phys., 3, 2225-2232, 2004 c.

Burrows, J., Weber, M., Buchwitz, M., Rozanov, V., LadstetterWeienmayer, A., Richter, A., DeBeek, R., Hoogen, R., Bramstedt, K., Eichmann, K. U., Eisinger, M., and Perner, D.: The Global Ozone Monitoring Experiment (GOME): Mission concept and first scientific results, J. Atmos. Sci., 56, 151-175, 1999. de Beek, R., Vountas, V., Rozanov, V., Richter, A., and Burrows, J. P.: The Ring effect in the cloudy atmosphere, Geophys. Res. Lett., 28, 721-772, 2001.

Fournier, N., Stammes, P., de Graaf, M., van der A, R., Piters, A., Grzegorski, M., and Kokhanovsky, A.: Improving cloud information over deserts from SCIAMACHY Oxygen A-band measurements, Atmos. Chem. Phys., 6, 163-172, 2006, http://www.atmos-chem-phys.net/6/163/2006/.

Grzegorski, M., Frankenberg, C., Platt, U., Wenig, M., Fournier, N., Stammes, P., and Wagner, T.: Determination of cloud parameters from SCIAMACHY data for the correction of tropospheric trace gases, in: ESA-publication SP-572 (CD-ROM), Proceedings of the ENVISAT \& ERS Symposium, 6-10 September 2004, Salzburg, Austria, 2004.

Joiner, J., Vasilkov, A. P., Flittner, D. E., and Gleason, J. F.: Retrieval of cloud pressure and oceanic chlorophyll content using Raman scattering in GOME ultraviolet spectra, J. Geophys. Res., 109(D1), D01109, doi:10.1029/2003JD003698, 2004.

Koelemeijer, R. B. A. and Stammes, P.: Validation of global ozane monitoring experiment cloud fractions relevant for accu- 
rate ozone column retrieval, J. Geophys. Res., 104D, 18 80118 814, 1999.

Koelemeijer, R. B. A. and Stammes, P.: Comparison of cloud retrievals from GOME and ATSR-2, ESA Earth Observation Quarterly, 65, 25-27, 2000.

Koelemeijer, R. B. A., Stammes, P., Hovenier, J. W., and de Haan, J. F.: A fast method for retrieval of cloud parameters using oxygen A band measurements from the global ozone monitoring experiment, J. Geophys. Res., 106D, 3475-3490, 2001.

Koelemeijer, R. B. A., Stammes, P., Hovenier, J. W., and de Haan, J. F.: Global distributions of effective cloud fraction and cloud top pressure derived from oxygen A band spectra measured by the Global Ozone Monitoring Experiment: comparison to ISCCP data, J. Geophys. Res., 107(D12), 4151, doi:10.1029/2001JD000840, 2002.

Koelemeijer, R. B. A., de Haan, J.F, and Stammes, P.: A database of spectral surface reflectivity in the range $335-772 \mathrm{~nm}$ derived from 5.5 years of GOME observations, J. Geophys. Res., 108(D2), 4070, doi:10.1029/2002JH002429, 2003.

Kokhanovsky, A. A., Rozanov, V. V., Zege, E. P., Bovensmann, H., and Burrows, J. P.: A semianalytical cloud retrieval algorithm using backscattered radiation in 0.4-2.4 $\mu \mathrm{m}$ spectral region, J. Geophys. Res., 108(D1), 4008, doi:10.1029/2001JD001543, 2003.

Krijger, J. M., Tanzi, C. P., Aben, I., and Paul, F.: Validation of GOME polarization measurements by method of limiting atmospheres, J. Geophys. Res., 110(D7), D07305, doi:10.1029/2004JD005184, 2005.

Krijger, J. M., van Weele, M., Aben, I., and Frey, R.: The effect of sensor resolution on the number of cloud-free observations from space, Atmos. Chem. Phys. Discuss, 6, 4465-4494, 2006.

Kurosu, T., Chance, K., and Spurr, R. J. D.: Cloud Retrieval Algorithm for the European Space Agency's Global Ozone Monitoring Experiment, in: Proceedings of SPIE, EUROPTO Series: Satellite Remote Sensing of Clouds and the Atmosphere III, edited by: Russel, J. E., 495, 17-26, 1998.

Kurosu, T., Chance, K., and Spurr, R. J. D.: CRAG - Cloud Retrieval Algorithm for the European Space Agency's Global Ozone Monitoring Experiment, in: Proceedings of the European Symposium of Atmospheric Measurements from Space (ESAMS), II, 513-521, 1999.

Kuze, A. and Chance, K. V.: Analysis of cloud-top height and cloud coverage from satellites using the $\mathrm{O}_{2} \mathrm{~A}$ and $\mathrm{B}$ bands, J. Geophys. Res., 99, 14 482-14 491, 1994.

Loyola, D.: A New Cloud Recognition Algorithm for Optical Sensors, in: IEEE International Geoscience and Remote Sensing Symposium, Seattle, II, 572-574, 1998.

Loyola, D.: Automatic Cloud Analysis from Polar-Orbiting Satellites Using Neural Network and Data Fusion Techniques, in: Proceedings of the IEEE International Geoscience and Remote Sensing Symposium, IGARSS'2004, Anchorage, vol. 4, pp. 25302534, 2004.
Platt, U.: Differential optical absorption spectroscopy (DOAS), Air Monitoring by Spectrometric Techniques, edited by: Sigrist, M., Chemical Analysis Series, John Wilsy, New York, 127, 27-84, 1994.

Rozanov, V. V. and Kokhanovsky, A. A.: Semianalytical cloud retrieval algorithm as applied to the cloud top altitude and the cloud geometrical thickness determination from top-of-atmosphere reflectance measurements in the oxygen A band, J. Geophys. Res., 109D5, D05202, doi:10.1029/2003JD004104, 2004.

Schiffer, R. and Rossow, W.: The international satellite cloud climatology project: The first project of the world climate research programme, Bulletin of the Amarican Meterological Society, 64, 779-784, 1983.

Schutgens, N. A. J. and Stammes, P.: A novel approach to the polarization correction of space borne spectrometers, J. Geophys. Res., 108(D7), 4229, doi:10.1029/2002JD002736, 2003.

Tuinder, O. N. E., de Winter-Sorkina, R., and Builtjes, P. J. H.: Retrieval methods of effective cloud cover from the GOME instrument: an intercomparision, Atmos. Chem. Phys., 4, 255-273, 2004, http://www.atmos-chem-phys.net/4/255/2004/.

v. Bargen, A., Kurosu, T. P., Chance, K., Loyola, D., Aberle, B., and Spurr, R. J.: Cloud retrieval algorithm for GOME (CRAG), European Space Agency (ESA/ESTEC), ESA/ESTEC, Noordwijk, the Netherlands, 2000.

Wagner, T., Beirle, S., v. Friedeburg, C., Hollwedel, J., Kraus, S., Wenig, M., Wilms-Grabe, W., Kuehl, S., and Platt, U.: Monitoring of trace gas emissions from space: tropospheric abundances of $\mathrm{BrO}, \mathrm{NO}_{2}, \mathrm{H}_{2} \mathrm{CO}, \mathrm{SO}_{2}, \mathrm{H}_{2} \mathrm{O}, \mathrm{O}_{2}$, and $\mathrm{O}_{4}$ as measured by GOME, vol. 10, Air Pollution 2002, WIT Press, 2002.

Wagner, T., Richter, A., v. Friedeburg, C., Wenig, M., and Platt, U.: Case Studies for the Investigation of Cloud Sensitive Parameters as Measured by GOME, in: TROPOSAT Final Report, Springer, Heidelberg, 2003.

Wagner, T., Beirle, S., Grzegorski, M., Sanghavi, S., and Platt, U.: El-Niño induced anomalies in global data sets of total column precipitable water and cloud cover derived from GOME on ERS-2, J. Geophys. Res., 110(D15), D15104, doi:10.1029/2005JD005972, 2005.

Wenig, M.: Satellite measurements of long-term global tropospheric trace gas distributions and source strength, $\mathrm{Ph} . \mathrm{D}$. thesis, University of Heidelberg, Germany, 2001.

Wenig, M. and Leue, C.: Cloud Classification Analyzing Image Sequences, in: Handbook of Computer Vision and Applications, edited by: Jaehne, B. and Haussecker, H., p. 652, Academic Press, London, 2000.

Wenig, M., Leue, C., Jaehne, B., and Platt, U.: Cloud Classification Using Image Sequances of GOME data, European Symposium on Atmospheric Measurements from space, European Space Agency, Noordwijk, The Netherlands, 1999. 